der aux personnes compétentes le volume-enquête que nous annonçons; il est éminemment pratique.

\title{
PAYS-BAS
}

\section{L'AMIRAL VAN KARNEBEEK}

La Croix rouge vient de perdre un de ses plus fermes soutiens dans les Pays-Bas, en la personne de M. le vice-amiral Jonckeer H. A. van Karnebeek, aide de camp de S. M. le roi, etc. Malgré son âge avancé, il avait pris uile part active à la Conférence de Paris, en 1867, comme délégué de la Société néerlandaise, puis à celle de Genève, en 1868, au nom de son gouvernement. Président, lors de cette dernière réunion, de la sous-commission maritime chargée de préparer la rédaction des articles additionnels à la Convention de Genève, il y travailla activement et fut pour beaucoup dans les résultats obtenus, grâce à son zèle et à ses connaissances spéciales. - Nous retrouvons encore l'amiral van Karnebeek à la Conférence de Berlin, en 1869; mais les membres de nos assemblées futures, privés de sa présence, regretteront certainement de ne plus voir ce vénérable et aimable collègne s'associer à leurs travaux.

\section{PRUSSE}

LES HOPITAUX ET. LES BARAQUEMENTS DE GUERRE A BERLIN PAR LE $D^{\mathrm{r}}$ STEINBERG

Le docteur Steinberg, qui plaida avec tant de chaleur et de zèle la cause des secours volontaires en mer, dans la Conférence internatio- 